\title{
A GESTÃO DE RECURSOS HÍDRICOS EM EMPREENDIMENTOS DE MÉDIO E GRANDE PORTE NA CIDADE DE VITÓRIA DA CONQUISTA - BAHIA
}

Gislane Nunes de Andrade - anny.nandrade@gmail.com IFBA - Instituto Federal de Educação, Ciência e Tecnologia da Bahia

Cristovão Figueredo de Souza - cristovaopiata@ hotmail.com IFBA - Instituto Federal de Educação, Ciência e Tecnologia da Bahia Jacson Tavares de Oliveira - jacson123@gmail.com

IFBA - Instituto Federal de Educação, Ciência e Tecnologia da Bahia

Leonardo Di Lauro Cunha Oliveira - leodilauroo@gmail.com IFBA - Instituto Federal de Educação, Ciência e Tecnologia da Bahia

Marilia de Jesus Oliveira - marilia.oliveira.vdc@ hotmail.com IFBA - Instituto Federal de Educação, Ciência e Tecnologia da Bahia 


\section{RESUMO}

Localizada na região sudoeste da Bahia, onde as reservas hídricas são escassas, a cidade de Vitória da Conquista enfrenta problemas com o racionamento de água desde 2012 e, concomitantemente com a construção de novos reservatórios, a gestão racional dos recursos hídricos surge como um instrumento fundamental para que a água seja utilizada da melhor forma, com o aproveitamento de água pluvial, o reuso de água residuária e a conscientização dos consumidores. O presente estudo objetivou avaliar a atual situação da gestão de recursos hídricos em empreendimentos de médio e grande porte no município de Vitória da Conquista-BA, identificando as deficiências do atual sistema para que sejam propostas novas técnicas e tecnologias de captação e reuso de água como medida corretiva. A metodologia adotada partiu de uma pesquisa bibliográfica sobre o tema e culminou com a aplicação de questionários nas empresas, sempre tendo como elemento norteador o texto constitucional da Lei $\mathrm{n}^{\circ} 9.433$, de 8 de janeiro de 1997. Os resultados da pesquisa permitiram verificar a multidimensionalidade da crise hídrica e o nível atual da gestão hídrica nos empreendimentos de médio e grande porte, com destaque para a questão da fonte utilizada, consumo, tipo de descarga, o aproveitamento de água pluvial, o reuso de água residuária e a conscientização dos consumidores.

\section{INTRODUÇÃO/OBJETIVO}

A escassez hídrica é um problema presente em quase todas as partes do globo terrestre. No Brasil, casos como o da cidade de São Paulo em 2014 e do Planalto Central em 2016 tomaram grande notoriedade. No entanto a cidade de Vitória da Conquista, localizada na região sudoeste da Bahia também passa por grave crise hídrica, enfrentando um pesado racionamento em 2012 e 2016/2017.

Essa problemática resulta do descompasso entre o aumento contínuo das demandas localizadas e a oferta real de água, situação consequente da forma desordenada com que os processos de urbanização, industrialização e expansão agrícola ocorreram a partir da década de 1950 (EMBRAPA, 2001). Aliado a isso, há, realmente, o componente climático, em que as chuvas estiveram abaixo da média, mas, sobretudo, ocorrem problemas de gestão em que o Estado, em seus diferentes níveis, não faz bem o seu planejamento estratégico para atuar na prevenção e defesa dos eventos críticos.

Segundo a Agência Nacional de Águas (2010), 55\% dos municípios brasileiros poderiam ter abastecimento deficitário até o ano 2015. A partir de um balanço de oferta e demanda, observou-se que $46 \%$ das sedes urbanas necessitam investimentos para soluções de problemas em seus sistemas produtores e $9 \%$ apresentam déficits decorrentes dos mananciais utilizados. As regiões Norte e Nordeste são as que possuem os maiores problemas nos sistemas produtores de água (mais de 59\% da rede urbana). A região Nordeste também se destaca com os maiores problemas de mananciais, principalmente, devido à escassez hídrica da sua porção semiárida. Nessa região, embora o número de sedes urbanas com sistemas de abastecimento de água em situação satisfatória até 2015 fosse de $26 \%$ do total, apenas $18 \%$ da população era atendida por 

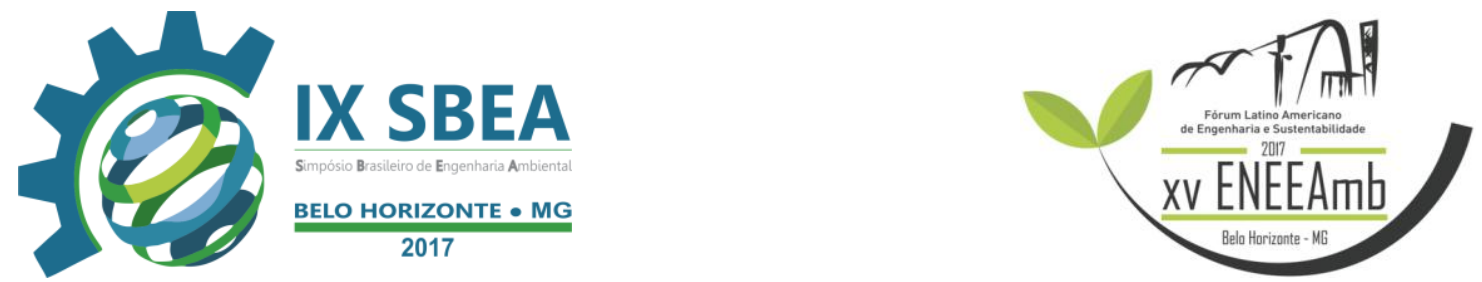

esses sistemas, sendo necessários investimentos para solução de problemas de abastecimento a $82 \%$ da população.

Aqui em Vitória da Conquista não é diferente. Localizada na região sudoeste da Bahia, a cidade também enfrenta problemas de escassez hídrica e está na lista dos 146 municípios em situação de emergência, segundo o Governo da Bahia, devido à estiagem. Nos últimos quatro anos, o município já foi obrigado a estabelecer um racionamento de água por duas vezes, sendo a primeira em 2012 e a segunda em 2016.

Segundo o gerente do escritório local da Empresa Baiana de Águas e Saneamento S.A - EMBASA, Álvaro Aguiar, a barragem de Água Fria II, uma das fontes de abastecimento de água do município de Vitória da Conquista, enfrentou uma queda abrupta do nível d'água neste ano de 2016. O nível de água da barragem atingiu uma cota limite de 61 metros, forçando assim o racionamento hídrico na cidade. Esse último racionamento foi ocasionado pela redução significativa na vazão do rio Catolé. $\mathrm{O}$ rio Catolé, que assegurava o abastecimento do município desde 2014, era responsável por $45 \%$ da vazão de alimentação. Entretanto, nos últimos meses, a adução abaixou para $20 \%$, dificultando a manutenção do regimento de abastecimento por parte da EMBASA. Álvaro ainda enfatiza que a solução para contornar a crise de abastecimento de água em Vitória da Conquista seria a construção da barragem do rio Catolé.

Além da escassez hídrica, a cidade de Vitória da Conquista apresenta um sério problema de drenagem urbana. As inundações, principalmente no centro da cidade, são recorrentes. Um dos empecilhos para um adequado dimensionamento do sistema de drenagem é o fato de não haver quantificação da intensidade, duração e frequência das chuvas, o que impossibilita a criação de projetos mais precisos. Há ainda falta de planejamento quanto à expansão urbana e ao uso do solo e a deficiência na rede coletora de esgoto, o que contribui para um estrangulamento de alguns pontos da rede de drenagem já que, muitas vezes, os esgotos domiciliar e comercial são direcionados para as redes de drenagem. A ineficiente coleta de resíduos e o descarte em local impróprio também geram transtornos devido ao entupimento de bueiros (SILVEIRA, 2009).

Diante desse contexto, a gestão de recursos hídricos surge como um instrumento para que a água seja utilizada da melhor forma. Algumas medidas utilizadas podem ser o aproveitamento de água pluvial, o reuso de água residuária e a conscientização dos consumidores.

O aproveitamento de água pluvial tem como principais vantagens à diminuição da demanda por água tratada, uma vez que esta pode ser usada em muitos fins que requerem pouco ou nenhum tratamento, como a limpeza de pisos ou descargas em banheiros, além disso, essa prática pode utilizar a estrutura já existente nas edificações como telhadas e lajes. Como desvantagem tem as variações pluviométricas, a dificuldade apresentada pelo usuário para manutenção do sistema e a necessidade de espaço nas edificações para implantação do sistema (SIMIONI et al, 2004).

Outra medida importante para o gerenciamento dos recursos hídricos é o reuso de águas residuárias. No Brasil o reuso de águas residuárias vem ganhando espaço principalmente nos grandes centros urbanos onde a escassez gera altos investimentos e custos operacionais para que seja realizada a captação e adução de águas às grandes distâncias. A atual crise hídrica enfrentada pelo país levou os usuários e empresas a rever as suas estratégias, com o objetivo de buscar alternativas de captação, tratamento e reciclagem que antes não eram utilizadas. 
Nesse contexto, o objetivo deste estudo foi avaliar a atual situação da gestão de recursos hídricos em empreendimentos de médio e grande porte no município de Vitória da Conquista-BA, identificando as deficiências do atual sistema para que sejam propostas novas técnicas e tecnologias de captação e reuso de água como medida corretiva.

\section{METODOLOGIA}

\section{Caracterização do objeto de Estudo}

O estudo se classifica como qualitativo descritivo, e foi conduzido na forma de um estudo de caso, para o qual foi aplicado um questionário, visando verificar a atual conjuntura da gestão de recursos hídricos no município de Vitória da Conquista.

Baseando-se em Aakear et al (2001), as perguntas do questionário foram elaboradas de modo a contemplar os seguintes aspectos: adequação aos objetivos; clareza da redação; caráter não indutivo e não ambíguo; atendimento a aspectos metodológicos gerais. O questionário foi estruturado com perguntas abertas e de múltipla escolha, seguindo uma ordem lógica de perguntas mais simples a perguntas mais complexas.

Assim, o estudo teve como foco os empreendimentos de médio e grande porte da zona urbana de Vitória da Conquista. Dentre esses, destacam-se: condomínios residenciais, condomínios comerciais (shopping e galerias) e empresas. A escolha foi feita tomando como base a representatividade do empreendimento para o município em termos de localização, número de residentes/trabalhadores e o percentual de área construída (mais que $200 \mathrm{~m}^{2}$ ). Por conseguinte, o questionário foi aplicado em: 1 condomínio residencial, 3 condomínios comerciais (1 shopping e 2 galerias) e 3 empresas.

Após a identificação das práticas de gestão dos recursos hídricos pelos empreendimentos, foi feita uma pesquisa bibliográfica em teses, artigos, livros e periódicos, a fim de identificar as melhores práticas/técnicas ou tecnologias para promover o aperfeiçoamento da gestão dos recursos hídricos.

\section{Caracterização da área de Estudo}

O município de Vitória da Conquista está localizado no Sudoeste da Bahia. A cidade possui uma área de $3.704 \mathrm{~km}^{2}$ e uma população estimada em 343.230 habitantes. Como se trata de uma capital regional, além da população residente, há que se considerar, também, a população flutuante proveniente de toda a região sudoeste que é atraída pelos serviços especializados da cidade, fato que impacta diretamente na gestão dos recursos hídricos. A temperatura média anual para o município é de $20^{\circ} \mathrm{C}$ com precipitações médias anuais de $712 \mathrm{~mm}$ (IBGE, 2010; CLIMATE-DATA, 2015). As "chuvas de neblina", como são chamadas, se concentram no período de abril a agosto. Já as "chuvas das águas" (mais intensas e fortes) ficam concentradas de outubro a março. (MEDEIROS, 2012).

Vitória da Conquista apresenta uma atividade rural consolidada e é referência regional nos setores de educação, saúde e comércio. A tendência é se afirmar cada vez mais como um polo importante de serviços rodoviários e como centro universitário e de 
pesquisas. Ainda em expansão, a "capital do sudoeste baiano" já é considerada uma grande cidade sob diversos aspectos (PEREIRA, 2013).

Com todo esse desenvolvimento, tem se tornado cada vez mais fortes as discussões e análises sobre os problemas de gestão dos recursos hídricos atuais e futuros. Atualmente, é bem notório que o crescimento somado a um consequente aumento populacional na cidade é inversamente proporcional ao seu potencial hídrico, ou seja, a quantidade de pessoas que utilizam desse recurso, seja qual for à fonte potável, é cada vez maior em relação ao que a região pode suportar.

A cidade está em uma região planáltica sobre um divisor de águas entre duas bacias: Rio Pardo e Rio de Contas. Além disso, o sistema de barragens (Biquinha, Água Fria e Serra Preta) instalado no município de Barra do Choça (Figura 1), é o principal responsável pelo abastecimento hídrico das cidades de Vitória da Conquista, Barra do Choça, Planalto e Belo Campo e das localidades de Barra Nova, Cafezal, Santo Antônio, Boa Vista, José Gonçalves, São Sebastião, Bate Pé, Pradoso e Iguá. Atualmente, esse sistema tem capacidade para armazenar 11 milhões de metros cúbicos de água, mas esse valor subirá para 35 milhões com a construção da barragem do Catolé Grande, prevista para 2020.

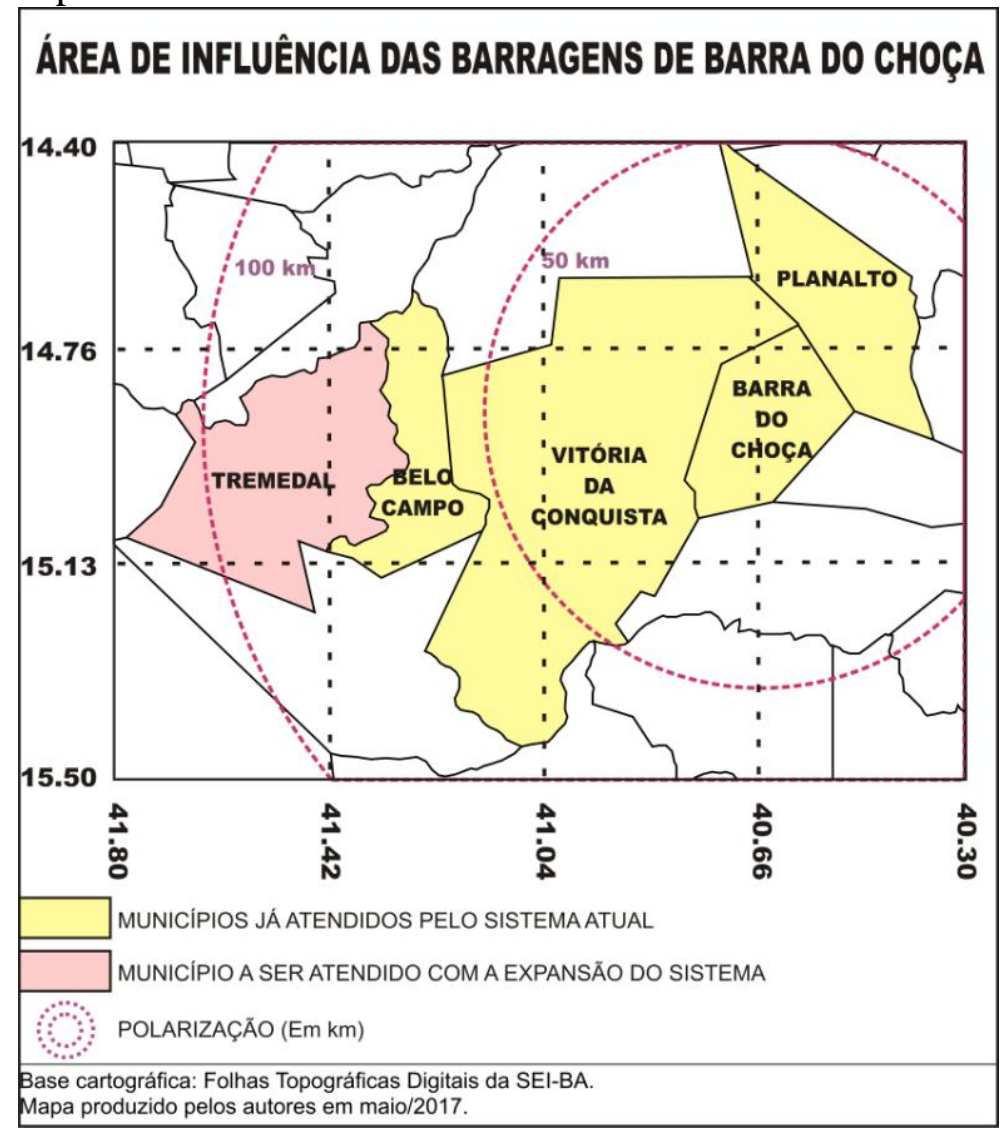

Figura 1- Área de influência do sistema de barragens instalado em Barra do Choça.

As bacias vêm sendo alvo de intensas atividades antrópicas, como salienta OLIVEIRA (2006):

Dentre as atividades antrópicas responsáveis por alterações na bacia de captação das barragens Água Fria I e II, podem ser citadas as queimadas, o 
desmatamento dos morros e nascentes, a destruição das matas ciliares e o destino irregular do lixo e dejetos. Estas ações têm promovido, ao longo dos anos, o assoreamento e a poluição dos cursos hídricos, o empobrecimento do solo, a aceleração de processos erosivos, o desaparecimento de espécies animais - principalmente da avifauna e ictiofauna, e o empobrecimento relativo da população, dentre outros prejuízos ecológicos e sociais.

O abastecimento de água no município é realizado pela Empresa Baiana de Águas e Saneamento S.A - EMBASA, desde 1973 (Bonfim et al, 2012), que capta a água bruta, monitora a qualidade da água nas fontes, como nos mananciais, para posterior tratamento e distribuição para as residências. Quando a água é captada de mananciais subterrâneos, ou seja, poços artesianos, a empresa faz somente a parte de desinfecção para depois distribuir (EMBASA 2015).

A segunda maior fonte a que a população recorre para o abastecimento de água são os poços artesianos, principalmente em grandes empresas, prédios comerciais, condomínios, loteamentos e demais setores ocupacionais que utilizam de um grande volume de água.

\section{RESULTADOS E DISCUSSÃO}

Numa região em que as reservas hídricas são escassas, onde predominam os climas úmidos a subúmido e subúmido a seco (SEI, 1998), a precipitação pluviométrica é o elemento climático mais importante, uma vez que a água é fundamental para o abastecimento humano, a dessedentação de animais, a manutenção das atividades econômicas de maneira geral, bem como determina a intensidade da vida animal e vegetal (BRASIL, 1981).

Compilando os totais pluviométricos de 1976 a 2016, é possível constatar que, nessa série histórica de 40 anos, apenas em três anos (1997, 2000 e 2004) os totais pluviométricos foram superiores a $1000 \mathrm{~mm}$ (Figura 2). Calculando a média aritmética no período 1976/2016, o resultado dá 718,4 mm.

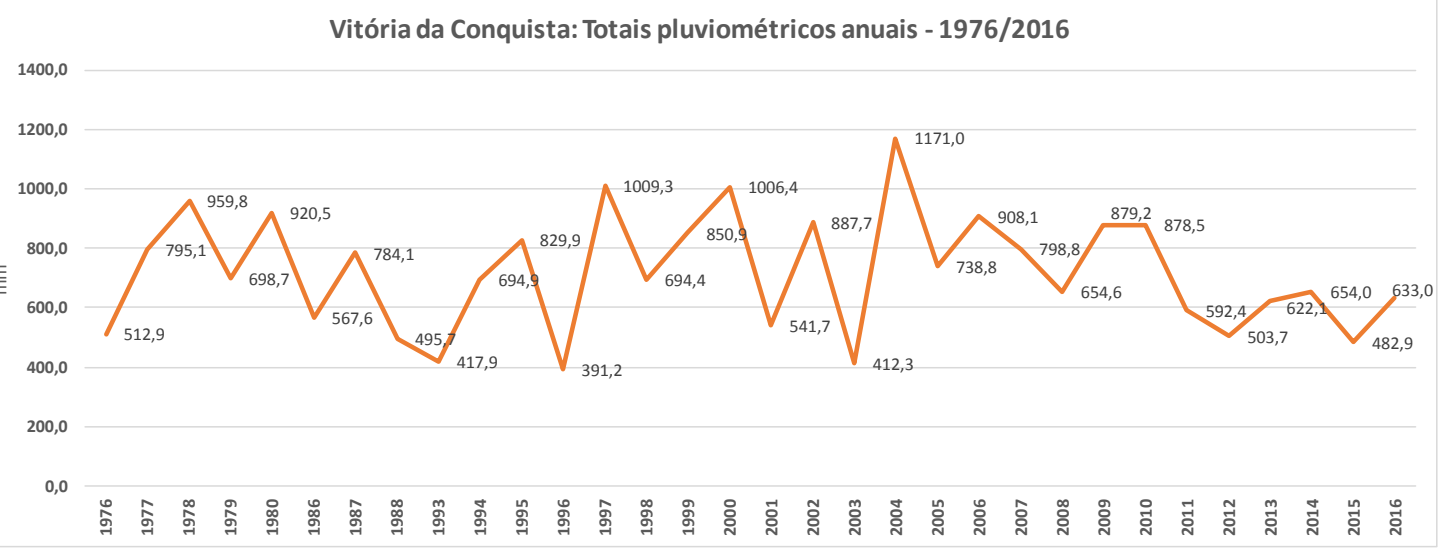

Figura 2 - Vitória da Conquista: Totais pluviométricos anuais - 1976/2016

Fonte: INMET, 2016 (Adaptado).

No entanto, a partir de 2005, os valores sempre estiveram abaixo do esperado, de forma que calculando a média no período 2005/2016, a quantidade de chuvas sofre uma redução de $3,2 \%(22,9 \mathrm{~mm})$, saindo de $718,4 \mathrm{~mm}$ para $695,5 \mathrm{~mm}$. A variabilidade climática da região apresenta como elemento limitador a escassez de água através de 
estiagens cíclicas e prolongadas, que impacta diretamente no abastecimento da cidade de Vitória da Conquista, assim como no desenvolvimento e expansão das atividades econômicas, com destaque para as agropecuárias.

A dimensão climática é importante, pois os dados mostram que nos últimos 12 anos as chuvas estiveram abaixo da média, mas isso não explica totalmente a crise hídrica, uma vez que as estiagens fazem parte das características climáticas regionais e essa variabilidade climática deve ser observada pelo Estado na elaboração e execução do seu planejamento estratégico, conforme item III do Artigo $2^{\circ}$ da Lei de Águas, que pressupõe a prevenção e a defesa contra eventos críticos de origem natural ou decorrentes do uso inadequado dos recursos naturais.

Nesse contexto, somando com a estiagem prolongada, há que se destacar a falha na função de planejamento estratégico do Estado em se antecipar à crise anunciada, uma vez que os dados já apontavam para o crescimento da demanda de água em função do crescimento populacional, industrial e agropecuário. A construção de um novo reservatório de água para abastecimento urbano não deveria ser emergencial, uma vez que são necessários vários anos para construir a barragem e depois ainda é preciso esperar um tempo não determinado para que as precipitações pluviométricas completem o serviço.

Assim, trata-se, também, de um problema de gestão, em que as diversas escalas do poder público falharam no atendimento aos objetivos propostos na Lei de Águas (Lei $\mathrm{n}^{\circ}$ 9.433/1997), notadamente garantir a oferta para os usos múltiplos, sendo que essa tarefa não envolve somente ampliar a captação/oferta de água, mas, sobretudo, fomentar o reuso reduzindo o desperdício pelos diferentes usuários (irrigação, indústria, residências, perdas, etc.) e programar medidas de conservação dos mananciais.

Dentro do objetivo geral desta pesquisa, percebe-se também que essa falha de gestão racional dos recursos hídricos encontra ressonância no setor privado. Considerando o tabelamento e a análise das informações colhidas nesta pesquisa, aborda-se agora a gestão de recursos hídricos em empreendimentos de médio e grande porte em Vitória da Conquista e a discussão sobre o nível de informação dos gestores dos empreendimentos selecionados nesse estudo acerca das legislações vigentes que regem este assunto.

Um dos primeiros pontos analisados foi à fonte de água utilizada. Detectou-se que as principais fontes de água são a concessionária (EMBASA) e os poços artesianos. Alguns dos empreendimentos não possuíam informações concretas sobre o volume mensal gasto de água e os que souberam informar deu uma estimativa de 800 a $900 \mathrm{~m}^{3}$ de água gastos mensalmente. Esse primeiro aspecto evidencia a falta de preocupação dos gestores quanto ao crescente consumo de água e sua possível escassez.

Outro ponto analisado no estudo foi o tipo de descarga utilizada nos empreendimentos, uma vez que, as bacias sanitárias consomem um volume de água considerável em relação ao consumo total de uma edificação. Estima-se que este consumo represente uma parcela na ordem de 30\%. Segundo Deboita e Back (2014) as bacias econômicas possuem descarga de duplo acionamento (dual), ou seja, consomem apenas 3 litros de água para remoção de dejetos líquidos e 6,8 litros para remoção de dejetos sólidos e líquidos. Verificou-se, no entanto, que apenas dois dos empreendimentos entrevistados utilizam este tipo de tecnologia. Contudo, estes dois 
empreendimentos em especial, são os mais recentes implantados na cidade, o que pode apontar para uma possível popularização desta tecnologia benéfica ao meio ambiente.

Percebeu-se ainda que os empreendimentos da cidade não utilizem sistema de captação de água da chuva, apresentando como justificativa o alto custo do investimento, a facilidade de se usufruir da água proveniente de poços artesianos e o baixo custo para utilização da água fornecida pela concessionária.

Além do reaproveitamento da água da chuva, a utilização de águas cinzas - as águas residuais não industriais e derivadas de processos domésticos - não foi vista entre os empreendedores locais. Esta técnica não vem sendo colocado em prática, pois, novamente, o fator preponderante, segundo os responsáveis pelos empreendimentos, é o alto custo. Todavia, pode-se destacar também a falta de conhecimento dos empreendimentos sobre a utilidade destas tecnologias, assim como aos créditos, descontos e incentivos fiscais oferecidos por grandes bancos para a implantação de sistemas como esses.

\section{CONCLUSÕES/RECOMENDAÇÕES}

Considerando a situação da cidade de Vitória da Conquista, os resultados desta pesquisa apontaram para um nível incipiente de conhecimento dos responsáveis pelos empreendimentos, com relação às ações sustentáveis de gestão dos recursos hídricos, incluindo os instrumentos legais de gestão como a Política Nacional de Recursos Hídricos (Lei n ${ }^{\circ}$ 9.433/1997). Em condições de escassez hídrica, a consciência é fundamental para evitar os desperdícios e aumentar a vida útil dos reservatórios disponíveis. Campanhas de conscientização extensivas e legislações específicas são alternativas para preparar melhor a população para eventos de racionamento ou até mesmo evitá-los, uma vez que a redução nos índices pluviométricos é uma realidade.

Os resultados apresentados também evidenciaram um déficit no conhecimento de tecnologias de reuso de água e suas vantagens econômicas e ambientais. Mais esclarecimento dos empreendedores e da população em geral facilitaria a gestão pública dos recursos hídricos por diminuir a carga sobre as estações de captação e tratamento pela adoção de práticas como as sugeridas.

Com o passar do tempo, a gestão dos recursos hídricos se tornará cada vez mais crucial para a manutenção da regularidade de abastecimento. Para conseguir aliar esta demanda crescente com o desenvolvimento socioeconômico, será necessário ampliar as ações de conscientização e incentivo às tecnologias mais eficientes, perpassando pelas esferas pública e privada.

\section{REFERÊNCIAS BIBLIOGRÁFICAS}

AAKER, D. A. Administração estratégica de mercado. Porto Alegre: Bookman, 2001.

BRASIL, Atlas; DE AGUA, Abastecimento Urbano. AGENCIA NACIONAL DE Águas. Resultados por Estado. Agência Nacional de Águas, v. 1, 2010. Disponível em: 
http://atlas.ana.gov.br/Atlas/downloads/atlas/Resumo\%20Executivo/Atlas\%20Brasil\%2 0-\%20Volume\%201\%20-\%20Panorama\%20Nacional.pdf. Acessado em: 13 mai. 2017.

BONFIM, Dirlêi A. et al. Considerações sobre as mudanças climáticas e os impactos na sub-bacia do rio Catolé para o município de Vitória da Conquista-Bahia. REMEARevista Eletrônica do Mestrado em Educação Ambiental, v. 29, 2012.

BRASIL. Ministério das Minas e Energia. Secretaria Geral. Projeto RADAMBRASIL: Folha SD.24 Salvador: geologia, geomorfologia, pedologia, vegetação e uso potencial da terra. Rio de Janeiro, 1981. 624p.

DEBOITA, Michele; BACK Nestor. Consumo de água em bacias sanitárias com a utilização de descarga de duplo acionamento: estudo de viabilidade econômica. 2015.

EMBRAPA- Empresa Brasileira de Pesquisa Agropecuária. Disponível em: www.embrapa.gov.br. Acessado em: 18 de maio de 2017.

EMPRESA BAIANA DE ÁGUAS E SANEAMENTO. Relatório Anual de Informação ao Consumidor. Vitória da Conquista e Belo Campo, 2015. Disponível em:<http://www.embasa.ba.gov.br/centralservicos/images/relatoriopcs/2015/USV/raic2 015_usv_vitoria_da_conquista_e_belo_campo.pdf> Acessado em 20 de maio de 2017.

LIMA, J. E. F. W. Recursos hídricos no Brasil e no mundo. Embrapa Cerrados, 2001. Disponível em: <http://ainfo.cnptia.embrapa.br/digital/bitstream/CPAC2010/23443/1/doc-33.pdf>. Acessado em: 20 mai. 2017.

INSTITUTO NACIONAL DE METEOROLOGIA. Banco de Dados Meteorológicos para Ensino e Pesquisa (BDMEP): Dados de estações meteorológicas. 1976/2016. Disponível em: <http://www.inmet.gov.br/portal/index.php?r=bdmep/bdmep>. Acesso em: 25 mar 2017.

IBGE - Instituto Brasileiro de Geografia e Estatística. Censo Demográfico 2010.

Disponível em: <http://cidades.ibge.gov.br/xtras/perfil.php?lang=\&codmun=293330\& search=bahia|vitoria-da-conquista $>$. Acessado em: 20 mai.2017.

MEDEIROS, R. H. A. Notas Críticas ao livro "O Município da Vitória" de Tranquilino Torres, p.67, 2012.

OLIVEIRA, Jacson Tavares de Evolução do Uso da Terra e dos Solos na Bacia de Captação da Barragem Água Fria I e II em Barra do Choça/BA. 2006. 112 p, il. 2006. Tese de Doutorado. Dissertação (Mestrado)-Universidade Estadual de Santa Cruz, Ilhéus.

PEREIRA, Francis José. A influência das grandes redes varejistas no comércio e na cidade: um estudo de caso sobre Vitória da Conquista. 2013. Tese de Doutorado. Universitat de Barcelona.

SUPERINTENDÊNCIA DE ESTUDOS ECONÔMICOS E SOCIAIS DA BAHIA. Geoinformação: Tipologia Climática segundo Thornthwaite - 1998. Disponível em: 
$<$ http://www.sei.ba.gov.br/index.php?option=com_content $\&$ view $=$ article $\&$ id=1901\&Ite mid=498>. Acesso em: 25 mar 2017.

SILVEIRA, Patrícia Amorim; PAIVA, Silva Gedeval. Análise dos impactos das precipitações no espaço urbano de Vitória da Conquista-Bahia: subsídios para um planejamento preventivo. 2009. Pesquisa Monográfica (Graduação em Geografia). Universidade do Estado da Bahia. Disponível em: <http:// periódicos.uesb.br/index. php/ascmpa/article/viewFile/3672/3357>

Acessado em: 13 mai. 2017.

SIMIONI, Wagner Isidoro; GHISI, Enedir; GÓMEZ, Luis Alberto. Potencial de Economia de Água Tratada Através do Aproveitamento de Águas Pluviais em Postos de Combustíveis: Estudos de Caso. In: Conferência Latino-Americana de Construção Sustentável. 2004. 